\title{
IDADE SUBJETIVA E AUTO-PERCEPÇÃO DE SAÚDE E BEM-ESTAR
}

Mariana de Medeiros Cardoso; Clínica Lavinsky; e-mail: fga.mariana.cardoso@gmail.com; Maira Rozenfeld Olchik, Universidade Federal do Rio Grande do Sul; mairarozenfeld@hotmail.com; Adriane Ribeiro Teixeira; Universidade Federal do Rio Grande do Sul e Universidade Federal de São Paulo; adriane.teixeira@gmail.com

\section{RESUMO}

Introdução: Sentir-se subjetivamente mais jovem do que a idade cronológica pode um ser marcador que reflita fatores biológicos. O uso de escalas de classificação numérica (ECN) também é uma das formas de se avaliar a auto-percepção de saúde e bem-estar dos idosos. Objetivo: Analisar a correlação entre idade subjetiva e a auto-percepção de saúde e bem-estar em idosos. Métodos: O estudo com delineamento retrospectivo, foi aprovado por Comitê de Ética em Pesquisa (Parecer $\mathrm{n}$ - 4.081.496). No momento da matricula em universidade aberta para pessoas idosas, os indivíduos respondiam a uma entrevista, onde, dentre as perguntas, estava o questionamento sobre idade subjetiva [quantos anos o(a) senhor(a) sente que tem?] e era solicitado que atribuísse uma nota de 1 a 5 para saúde, bem estar, memória e estado físico. Os dados foram analisados de forma quantitativa, descritas por média e desvio padrão e coeficiente de correlação de Spearman. Resultados: Foram analisados dados de 395 idosos, sendo 359 mulheres (90,9\%), com idades cronológicas entre 60 e 91 anos (média 71,5 56,8 anos). A média da idade subjetiva da amostra ficou em 57,2 $\pm 14,0$ anos. No que se refere a avaliação de saúde e bem estar, pela ECN, maior parte dos idosos atribuiu as notas 4 ou 5 para os itens saúde $(81,8 \%)$, bem estar $(87,6 \%)$, memória $(69,9 \%)$ e estado físico (81,5\%). Verificou-se correlação significativa somente entre a idade subjetiva e a saúde percebida ( $r s=-0,149 ; p=0,003)$. Conclusão: A análise dos dados evidenciou que a saúde percebida está correlacionada com a idade subjetiva, nos indivíduos avaliados.

Palavras-chave: Idoso; Envelhecimento; Saúde 